Hydraulic Engineering Repository

Ein Service der Bundesanstalt für Wasserbau

Kovalevsky, Dmitry; Scheffran, Jürgen

Coastal Cities Affected by Sea Level Rise and Forrester's 'Urban Dynamics'

Zur Verfügung gestellt in Kooperation mit / Provided in Cooperation with:

Deutsche Meteorologische Gesellschaft

Verfügbar unter / Available at:

https://hdl.handle.net/20.500.11970/108212

Vorgeschlagene Zitierweise / Suggested citation:

Kovalevsky, Dmitry; Scheffran, Jürgen (2021): Coastal Cities Affected by Sea Level Rise and Forrester's 'Urban Dynamics'. Poster präsentiert bei: 12. Deutsche Klimatagung, Online-Tagung, 15. bis 18. März 2021. https://doi.org/10.5194/dkt-12-14. 


\section{Coastal Cities Affected by Sea Level Rise and Forrester's 'Urban Dynamics'}

\section{Dmitry Kovalevskya , Jürgen Scheffran ${ }^{b}$}

a Climate Service Center Germany (GERICS), Helmholtz-Zentrum Geesthacht, Hamburg, Germany (dmitrii.kovalevskii@hzg.de)

${ }^{b}$ Research Group Climate Change and Security (CLISEC), Institute of Geography, Center for Earth System Research and Sustainability (CEN), Universität Hamburg, Germany

$\checkmark$ System dynamics (SD) is a powerful modelling approach for 'what-if' simulations in climate and environmental problems

$\checkmark$ To describe the pathways of coastal urban adaptation, we develop two modifications of the seminal Forrester's 'Urban Dynamics' model

$\checkmark$ Currently, these modifications are tailored to simulate the 'business-as-usual' $(\mathrm{BaU})$ coastal urban scenario with no adaptation actions
In our extensions of Forrester model, sea level rise and related coastal hazards lead to a gradual reduction of city area and severe damages to urban infrastructure

$\checkmark$ Our simulations tell us a narrative of urban decline under $\mathrm{BaU}$ - as opposed to Forrester's original simulations where the urban system converges to equilibrium

$\checkmark$ We also develop simple reduced models of the dynamics of urban wealth that are in qualitative agreement with the results of our modifications of the Forrester model
Forrester's 'Urban Dynamics': a simplified structure Adopted from (Stonebraker, 1972), with simplifications

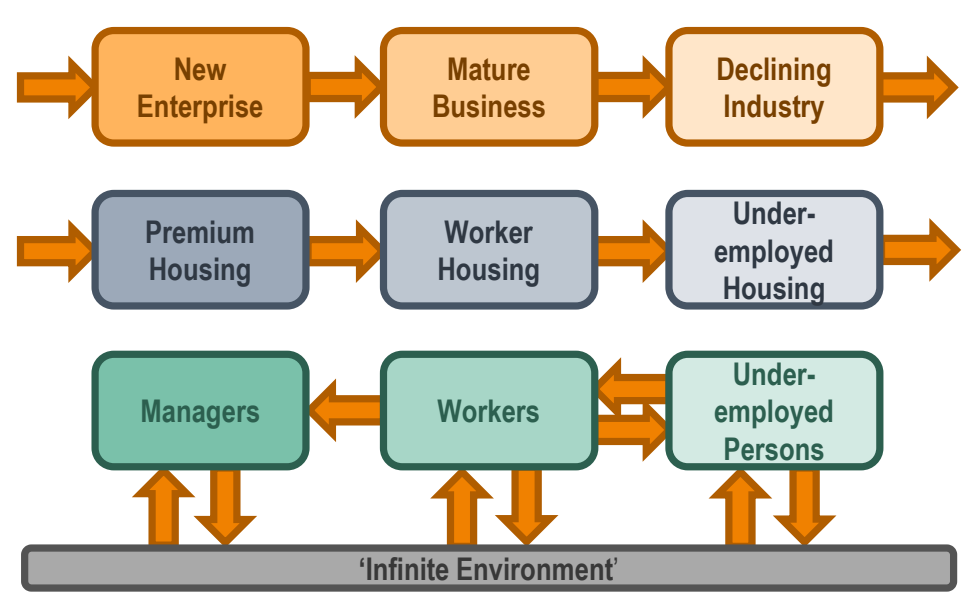

Simulated dynamics of coastal urban industry

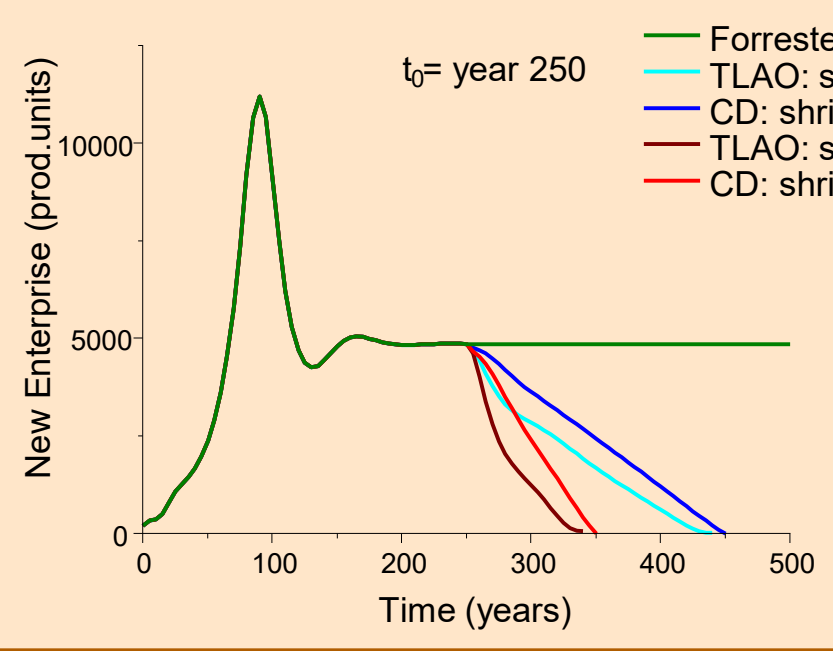

SD model modifications: TLAO: 'Total Land Area Only'

CD: 'Coastal

Depreciation'
Acknowledgements: This work was conducted and financed in the project "Modelling Urban Dynamics Affected by Climate Change for Coastal Spatial Planning and Management" (MUCCCS) within the framework of the Helmholtz Institute for Climate Service Science (HICSS), a cooperation between Climate Service Center Germany (GERICS) and Universität Hamburg, Germany 